\title{
Connecting to the trail: Natural spaces as places of healing
}

By: Justin Harmon and Gerard Kyle

Harmon, J., \& Kyle, G.T. (2020). Connecting to the trail: Natural spaces as places of healing. Leisure Sciences. doi: 10.1080/01490400.2020.1712282

This is an Accepted Manuscript of an article published by Taylor \& Francis in Leisure Sciences on 13 January 2020, available online: http://www.tandfonline.com/10.1080/01490400.2020.1712282.

***:(C) 2020 Taylor \& Francis Group, LLC. Reprinted with permission. No further reproduction is authorized without written permission from Taylor \& Francis. This version of the document is not the version of record. ***

\section{Abstract:}

The concept of "place" has been explored for decades, examining how specific geographic locales impact social meanings and interactions, sentimentality associated with a specific environment, and the construction of identity through prolonged place interaction. While meanings often differ based on individual history and interactions, physical environments are often symbolic; they may come to embody elements of potential, catharsis, restoration, or opportunity. In the context of nature, the diversity of meaning is often evidenced by an individual or groups' reverence for the natural place to their perceived quality of life. This study sought to explore how those diagnosed with cancer use natural spaces as a supportive resource in their healing process. As will be demonstrated, the profound benefit of repeated exposure to restorative natural environments for those diagnosed with cancer establishes how natural spaces become places of healing for people with serious illnesses.

Keywords: cancer $\mid$ hiking | place meaning

Article:

Laurel Bluff is my favorite trail. After I get up to the top of that steep incline, I need a breather, but it really feels like I've accomplished something. I guess it's kind of like that stupid cancer (laughs): I had to climb the hills of chemotherapy, radiation, and surgery, but once I had, I could look back and see what I had come through. Although, I'm not looking to go back through all that again. I'll just stick with these trails - that's the only challenge I'm looking for these days! - Paula (70, breast cancer, double mastectomy)

\section{Introduction}

The concept of "place" has been explored for decades, examining how specific geographic locales impact social meanings and interactions, sentimentality associated with built and natural environments, and the construction of identity through prolonged place interaction (e.g., Buttimer \& Seamon, 1980; Giuliani \& Feldman, 1993; Tuan, 1980). Related, the literature on 
place sentimentality has considered variants such as "place attachment" (Low \& Altman, 1992), the duality of "place identity" and "place dependence" (Williams, Patterson, Roggenbuck, \& Watson, 1992), and "sense of place" (Hay, 1998) to articulate what it is about places that underlies a person's connections to the landscape.

A number of authors (Greider \& Garkovich, 1994; Kyle \& Chick, 2007; Milligan, 1998; Stokowski, 2002) have noted that social constructivist orientations provide an effective framework for understanding how people find meaning in a variety of landscapes. The meanings assigned to these attributes can often differ based on individual and collective histories. In this way, the physical environment is symbolic; textured by memory, history, and experience. The implications for understanding people's relationship with place, then, suggests that settings can hold multiple values somewhat independent of physical form. This is not to say the physical form is irrelevant. Most would acknowledge place attributes are integral to the way in which people interact with the landscape and one another. Ocean, mountain, and desert environments impact us physically, emotionally, and socially. Their impact, however, is not uniform. Our interpretation of the attributes that constitute these settings is rooted in our ancestry, experience, and memory.

While extreme social constructivist perspectives on place meaning have been criticized (Crist, Center for Environmental Philosophy, \& The University of North Texas, 2004; Proctor, 1998), the interpretation of individuals and collectives can be anchored in a diverse array of factors, some of which are shaped by setting attributes (e.g., exceptional kayaking, surfing, climbing) and some independent of form (e.g., childhood memory, experience with family/friends). Most important, the attraction (or aversion) of people to place is based on the meanings they associate with the setting. In the context of nature, the diversity of meaning is evidenced in some groups' aversion to wildland settings (Johnson, 1998) and others eulogizing its value (Rolston, 2001). The subjectivity of place meaning also allows for the possibility of heterogeneity in the benefits people derive from interacting with natural landscapes (Kyle, Mowen, \& Tarrant, 2004). This is especially true for people affected by serious illnesses (Twohig-Bennett \& Jones, 2018).

In the context of people with cancer, those diagnosed often associate the clinical setting where they were diagnosed and treated with meanings of negativity (Harmon, 2019; Johansson, Axelsson, Berndtsson, \& Brink, 2014). Beyond the emotional impact of the diagnosis, the negativity is often reinforced by other survivors' propensity to emphasize the negative aspects of life with cancer in support groups (Winefield, Coventry, Lewis, \& Harvey, 2003). The result is an extreme place aversion where many are reluctant to return to the hospital for non-medicinal support (i.e., therapy groups) because the clinical atmosphere is traumatizing. This suggests that places can carry negative identities or meanings for some, leaving those diagnosed with cancer in need of other outlets to find positive meaning as they cope with their illness.

Continued investigations on the topic of place have led to greater focus on the complementary concept of "restoration" which is often sought, and found, through immersion in nature (Hartig, Mang, \& Evans, 1991; Korpela, Ylén, Tyrväinen, \& Silvennoinen, 2008; Östergren, Björk, Grahn, Skärbäck, \& Währborg, 2012). Other scholars have explored the nature-wellbeing connection through the concept of "connectedness" (Howell, Passmore, \& Buro, 2013), defined 
as an "individual's experiential sense of oneness with the world" (Mayer \& Frantz, 2004, p. 504).

For those diagnosed with cancer, immersive natural environments, such as forests with hiking trails, can provide both a place, and an activity, that is beneficial and restorative to the stressful aspects of cancer treatment and recovery (Cimprich \& Ronis, 2003; Harmon, 2019). Nature and green spaces are frequently acknowledged as providing enhanced opportunities for physical activity which has been linked to other positive psychological and physiological benefits (Kaplan, 1995; Mitchell \& Popham, 2008; Nutsford, Pearson, \& Kingham, 2013; Östergren et al., 2012). This is especially important for people who have been diagnosed with a serious illness like cancer. Numerous studies point to the profound benefit to those in treatment for cancer receive through repeated exposure to restorative natural environments (Morita et al., 2007; Song, Ikei, \& Miyazaki, 2016), as well as through engaging in physical activity in green spaces (Lee et al., 2014).

Because cancer diagnoses are disruptive to routines and everyday functionality (Cimprich \& Ronis, 2003; Morris, Campbell, Dwyer, Dunn, \& Chambers, 2011), there exists a need for further exploration of the support mechanisms that can help restore peace of mind, reduce stress, and aid in the normalization process of life with, and after, cancer (Campbell, Phaneuf, \& Deane, 2004), especially through immersion in natural environments (Lee et al., 2014; Wolsko \& Hoyt, 2012). The term "survivor" is used here to refer to those diagnosed with cancer, regardless of stage or status (i.e., in remission or still in treatment; Connerty \& Knott, 2013). With this in mind, this investigation sought to address two questions: a) does regular participation in a hiking group for survivors of cancer improve perceived wellbeing? and b) do cancer survivors develop/build on positive meanings for natural environments as they negotiate their illness?

\section{Literature review}

Hiking as support and healing

Hiking is a non-consumptive activity where the primary focus is the enjoyment of the natural environment (Svarstad, 2010). Depending on trail proximity, hiking is an easily accessible activity that requires little in the way of training or resources (Fesenmaier, Goodchild, \& Lieber, 1981). As immersion in natural environments has been linked to higher reports of perceived wellbeing (Capaldi, Passmore, Nisbet, Zelenski, \& Dopko, 2015), this suggests that the activity of hiking, and the setting in which it takes place, can be beneficial for improving one's mental health (Mayer, Frantz, Bruehlman-Senecal, \& Dolliver, 2009), especially for those with serious illnesses or injuries (Goodwin, Peco, \& Ginther, 2009; Harmon, 2019). Studies have established that hiking can impart feelings of attachment to the natural environment, in large part because of the way it positively impacts the hiker's mood and feelings of satisfaction (Hull \& Stewart, 1995; Kyle, Graefe, Manning, \& Bacon, 2003).

Physical activity in natural environments, like hiking, for those with cancer is part of a salutogenic approach to treating those with chronic illnesses, in that it is more holistic than pathogenic strategies that have been employed for centuries (Jonas, Beckner, \& Coulter, 2006). The salutogenic process emphasizes stress reduction and wellbeing through the exploration of 
the link between health and coping strategies (Abedalaal \& Soebarto, 2019), thus suggesting that the potential to improve mental and emotional health through hiking for those with serious illnesses like cancer if greatly enhanced (Baklien, Ytterhus, \& Bongaardt, 2016).

If people with cancer find healing and strength through hiking, they may perceive the natural environment as a valued resource in their journey, independent of the extent of their appreciation of nature pre-diagnosis (Mitchell \& Popham, 2008). When the activity of hiking is done with others who have experienced similar life hardships, it can provide great benefit (Cimprich \& Ronis, 2003). While sharing the hiking experience with others affected by cancer does not eliminate the potential to speak about the negative aspects of illness and treatment, that the activity takes place outdoors and away from medicalized venues may help alleviate some of the emphasis from the illness experience to a focus on the wellness experience associated with hiking (Harmon, 2019).

Nature-based therapy

People diagnosed with cancer are often provided with a number of options for support as they go through treatment and seek their "new normal" after remission (Hoey, Ieropoli, White, \& Jefford, 2008). Many, however, find the structure and focus of "traditional" support groups not to their liking, oftentimes because the focus is on illness and not wellness (Winefield et al., 2003). Additionally, given that many support groups are held in the same place where diagnosis and treatment occur, some survivors of cancer are averse to returning to those medicalized environments (Harmon, 2019; Johansson et al., 2014). Because of this, nontraditional forms of support, like hiking groups, can be of great value to those in treatment, or remission, from cancer (Lee et al., 2014; Song et al., 2016), as well as those no longer seeking treatment, including those in palliative care (Fegg et al., 2010).

\section{Restorative environments}

There are two overarching theories that provide insight on the restorative aspects of nature, the first being Kaplan and Kaplan (1989) attention-restoration theory (ART), which focuses on the reduction of fatigue through the elicitation of fascination, a sense of temporary escape, a feeling of connectedness to a bigger picture, and compatibility between the person and the environment. The second, Ulrich's (1979) psychophysiological stress reduction framework, puts forth the notion that the natural environment has a calming effect that is inherently reinvigorating and summons positive emotional states that override negative sensations. While there are distinctions between these two theories, it is the elements the two theories have in common which is the focus of the current investigation. Specifically, nature's ability to promote restoration and recovery from an inability to concentrate (Ulrich, 1979), and from the elevated physiological arousal and negative emotions stemming from acute stress and fatigue (Kaplan \& Kaplan, 1989).

In a concise review of the literature related to these theories, Korpela, De Bloom, and Kinnunen (2015) demonstrated that the "demands of life" innately diminish the psychological and physiological capabilities of individuals, thus suggesting that the perception of restoration many find in natural environments can be beneficial for initiating "recovery" to pre-stressor levels (i.e., pre-diagnosis), something that can be imperative to the comprehensive health of someone with 
cancer (p. 216). Of relevance to this line of thinking are concepts such as biophilia and topophilia. Wilson (1993) described biophilia as, "the innately emotional affiliation of humans to other living organisms" (p. 31), suggesting that the natural environment is essential to the health and wellbeing of humankind (Beery, Jönsson, \& Elmberg, 2015). The concept of topophilia builds upon that of biophilia, seeking to couple sentiment with place, "to include all of human beings' affective ties with the material environment” (Tuan, 1973, p. 93).

Given the focus of this manuscript is on how people with cancer find meaning and develop an attachment to a local trail system they hiked on a weekly basis, it is worth noting the importance of trail planning and the public valuation of green space to the ability of participants to feel this sense of connection. Greider and Garkovich (1994) indicated that the "landscape" of natural environments possess properties that allow people to find meaning based on their interests or experiences, and these meanings are often derivative of cultural identities and preferences some people (or locales) may put higher value on green space and the ability to access it.

This study took place in a U.S. city, and therefore the "value of nature" attributed to the analysis is a contemporary Western characterization. In the United States, the existence and accessibility of trails are made possible through human intervention to help cultivate or emphasize the restorative outcomes inherent in natural environments, and may result in being perceived as "therapeutic landscapes" to those who use them (Hartig et al., 1991; Park, Furuya, Kasetani, Takayama, Kagawa, \& Miyazaki, 2011; Williams, 2002). Equally important is the abundance of nature that envelops the trails - and the hikers - as they work through their healing process and build their connection to natural environments (Song et al., 2016; Wolsko \& Hoyt, 2012). Therefore, the "ecotone" of the trail system bridges together the urban and the wild, allowing nature lovers, including hikers, to channel their innate biological connection to the natural environment (Lee et al., 2014). That nature is an inherently revitalizing phenomenon - it is restorative in its own right - may signal to its users, especially those with serious illnesses like cancer, that they, too, can find restoration through immersion in natural settings (Kaplan, 1995; Korpela et al., 2008).

\section{Methods}

\section{Background of study}

The first author started a hiking program for people with cancer, survivors, and their caregivers which meets twice weekly, on Wednesdays and Saturdays, year-round. Weekend hikes are roughly four miles and geared toward individuals who may still be working and individuals with higher levels of physical ability. Midweek hikes are intended to be slower-paced and for those not working, but more often than not, the participants are just as able-bodied and determined as the weekend group. There have been more than fifty participants to date, with twenty-one having participated on at least twenty hikes.

Participants are referred to the program from the nearby cancer center by oncologists and clinical social workers. The hiking program does not focus on the cancer experience or treatment in that participants are not expected to talk about their illness or treatment regimen. It is implicit why people are there; they have been diagnosed with cancer. Participants do, however, often talk 
candidly about their illness experiences while hiking. Oftentimes, the hikers will confide in the first author about the benefits they derive from participation, directly and indirectly referring to their involvement as therapeutic due to the healing they find through hiking. All participants are informed about the research activity being undertaken by the first author prior to joining the hiking program, as well as being told there is no requirement or expectation to participate in the research. The informed consent and interview guides were approved by the university's institutional review board (IRB).

There are approximately 25 trails in "rotation" for the group, all within a 15-25 minute drive from the city center. Most are managed by the city. Trails range in length from two to eight miles, and most are out-and-back, though a few are loops. There is very little elevation change, though a few trails do have some slight climbs. Finally, most trails are accessible from roadside parking on the edges of the city, though several are in more remote areas, thus lending to the immersion aspects of nature many covet.

Participants

Interviews were conducted with twelve participants, two males and ten females, with an average age of 67 years old (with the youngest being 58 and the oldest being 73). All participants either had cancer or were in remission. Nine of the participants were white, two were black, and one Hispanic. Pseudonyms were assigned to protect identity. Hikers were told about the first author's research agenda on their first hike, though they were not asked to participate in an interview until they had been out on a minimum of ten hikes. The first author thought it necessary to first build familiarity between the researcher and the prospective participant, in addition to determining the level of interest and commitment on the part of the hiker. Consequently, participants were chosen using purposive sampling (Patton, 1990) based on informal discussions shared while hiking about their experiences with cancer and the importance of hiking and the trail system to their lives.

Participant observation and informal discussions

The first author undertook this investigation as both a participant and an observer. He participated in the majority of hikes and was assisted by graduate students in his absence to facilitate the hikes. As an observer, the first author made mental notes during participation in order to write up more expansive field notes after each hike (Tracy, 2013). The informal discussions that took place on hikes often led to topics to be followed up on, as well as specific issues to address with participants at interviews. All notes then became a part of a larger field journal for the project. The field journal contained notes from more than sixty hikes with the hiking program.

\section{Interviews}

Semi-structured interviews were conducted with each participant following a pre-established set of questions to understand their historical relationship to nature and leisure, their diagnosis of cancer and accompanying treatment program, participation in the hiking program, and their outlook for the future. Key questions asked included: How important is being in natural 
environments to your quality of life? How would you describe yourself pre-diagnosis of cancer? How would you describe yourself after diagnosis? What have been the best support mechanisms in your recovery process? And, has hiking and/or the trail system been important to your recovery? Interviews were conducted in public spaces of the participants' choosing. Interviews typically lasted about an hour, though several lasted up to two hours. All interviews were recorded and transcribed by the first author.

Data analysis, interpretation, and representation

Data analysis occurred through a back-and-forth examination of data to determine if and how involvement in the hiking program, and exposure to restorative environments more broadly, had been beneficial to individuals' "normalization" process of life with/after cancer (Crotty, 2010). The concept of place attachment emerged from the data, and was not the intentional focus of interviews. We were interested in developing a better understanding about what transpired for the hikers in the group. Participants began to speak about the value of the trails and forests to their perceived wellbeing and it became clear that frequent immersion and familiarity led to a sense of attachment.

The analysis process, then, was both inductive and deductive, and used a primary and secondary coding technique which was derived from thorough re-readings of the interview transcripts and field notes, making notes and categories of patterns and comments of interest. Primary codes were then grouped into specific categories using focused coding (Tracy, 2013), which resulted in two overarching themes: perceived wellbeing, and the importance of the trail system. The analysis required the authors to develop an understanding of the personal story of cancer from diagnosis through treatment, and as applicable, remission or health maintenance as it applied to the study's purpose. The data were managed by establishing which content spoke to the research question, and then grouping the data into themes (Saldaña, 2012).

\section{Trustworthiness}

Validity and reliability were established for this study through member checks and external expert review from the second author who was not involved in data collection or the hiking program (Crotty, 2010). The first author both conducted the interviews and informally spoke with each of the participants on several subsequent hikes once the analysis and writing process commenced. The purpose of this was to confirm the accuracy of how the data were interpreted.

\section{Results and discussion ${ }^{1}$}

Whenever I miss a week or two hiking with the group, I'm out of sorts. It's amazing how two hours on a trail can improve my mood for the rest of the week. I really do think these trails are a blessing. More people should use them; we might have less problems in the world! But in all seriousness, these trails have helped me become healthy again; and I'm deeply grateful for that. Glenda (68, breast/cervical cancer)

Hiking and improved well-being 
The participants of this study have either been through harrowing battles with cancer or are still enduring them. While the majority have had some experience with hiking in their lives, most did not hike with much frequency until joining the group. In fact, several had not been hiking in decades even though the trail system was nearby. The motivation for most to join the program usually included two equally-weighted reasons: 1) an opportunity to become physically active and attend to their health needs, and 2) their felt connection to the natural environment, even if they had not been immersed in nature in quite some time. With regard to the former, Lee and colleagues (2014) established the connection between exercise in natural environments and improvement in health status. Related to the latter, Scannell and Gifford (2010) stated that place meaning and attachment is often built over time, thus connecting people to past memories of immersion in natural environments that cause nature to continue to be important into the future (Ratcliffe \& Korpela, 2016). This was illustrated by Bill (71, prostate cancer) when he said,

I've been driving by some of these trails for 30 years, and most of them I hadn't been on before joining the group. But every time I passed one, I'd think about my youth and how much time I spent in the woods; it truly was my sanctuary. I think that was always at the back of my mind as I drove by. Now that I'm out almost every weekend, I'm sure of it. I feel a connection to my past, but I also feel like being active in improving my health. It's a win-win.

As cancer diagnosis and treatment is fraught with physiological and psychological outcomes, those affected by the disease are prone to having higher levels of stress, anxiety, and depressive symptoms (Morita et al., 2007; Park, Chmielewski, \& Blank, 2010). Because of this, the inherent restorative properties of nature and physical activity in nature can be especially beneficial to this population (Ottosson \& Grahn, 2005), and can also be beneficial to social reintegration postdiagnosis (Gianinazzi et al., 2016). Annie (67, breast cancer) was almost literally "prescribed" the hiking program by her oncologist. When she met with him, he asked her what she was going to do to stay active, and she said she was unsure but wanted to be outdoors. Her doctor told her about the hiking group and she came out one week later. Annie said that, "I just couldn't be cooped up any longer, and my doctor told me I needed to not accept defeat, so I didn't. I have always enjoyed walking, but I didn't realize how much I would love hiking." Korpela et al. (2008) indicated that the three most likely determinants of restorative experiences are physical activity, exposure to nature, and a sense of being safe, all three of which were found by Annie through her participation in the hiking program.

The latter factor of Korpela et al. (2008), safety - feeling secure in a place or with a group, is closely linked to the importance of social support for people affected by cancer (Campbell et al., 2004; Ussher, Kirsten, Butow, \& Sandoval, 2006). Lana (58, breast cancer) and Clara (59, breast cancer) were former neighbors years ago who used to enjoy walking together. But once they moved away from one another, and their kids demanded more of their time, they fell out of practice in their walking regimen. Clara was diagnosed with cancer first, and Lana came back into her life about that time. Toward the end of Clara's treatment period, Lana was diagnosed, so they had yet another reason to bond. Both acknowledged having fallen out of healthy lifestyles, especially in regards to exercise, so with the support of one another they joined the hiking program. Korpela et al. (2008) emphasized that natural environments are inherently social in that they stimulate awe and wonder and provide a backdrop to share meaningful experiences with 
friends and family. Because of this, natural environments are also especially conducive to stimulating conversation which can be beneficial in its own right for those with serious illnesses (Wolsko \& Hoyt, 2012). For Clara and Lana, they found their time spent on the trails to allow them to cope with their life changes in a social, healthy forum, which helped them to play an active role in defining the negative life event of cancer (Kleiber, Hutchinson, \& Williams, 2002). Lana may have put it best when she said,

It's easy for me to wallow in the [cancer] diagnosis. I can sometimes just sit around, watching TV, feeling down. But when I have something enjoyable and healthy to do, it gets me moving. I've found that hiking on Saturdays really energizes me, and that is important. Now I go out on these trails, I feel healthier, I appreciate their beauty; it's always a positive experience.

Numerous scholars have pointed to the potential of leisure activities, like hiking, to be essential to the healing process of posttraumatic growth (Janke \& Jones, 2016; Morris et al., 2011; Tedeschi \& Calhoun, 2004). Clara put it succinctly when she said, "Cancer was a real wakeup call. Everything that was really important to me came back front and center. Besides my kids, the next most important thing was my health and my friends, with being in nature right after. Now I've got the opportunity to hike with old and new friends every week and improve my health. I couldn't say that without these beautiful trails here." For Clara, and the other participants, the activity of hiking and the trail system they relied on, allowed them to attend to issues of identity, friendship, improving health, and overall sense of wellbeing, something that most acknowledged would not be as easily accessible without nature at their backdoor. While the diagnosis and treatment were challenging, if not crippling, for the participants, each found strength in taking the necessary steps to improve their situation, even in light of the ambiguity surrounding their diagnosis (Antoni et al., 2001; Scrignaro, Barni, \& Magrin, 2011).

Positive meanings from natural places

Maas, van Dillen, Verheij, \& Groenewegen (2009) found that loneliness and/or lack of social support are negatively related to people's perceived health. Because of this, it may be helpful for those with cancer to have support in an array of options and different activities (Connerty \& Knott, 2013). Glenda had always been active, up until her first cancer diagnosis, and after that she was more cautious in her activities. When she was diagnosed a second time, and would never be "cured" as she is Stage IV, she felt that many of the things that were important to her in life were now no longer available. However, her doctor asked her why she could no longer swim, ride bikes, or, most importantly, hike; her response was, "Yeah, why can't I?"

Glenda, who loved to "touch trees" and be in their presence, was eager to come out with the group to reinvigorate her love of nature. Her husband is active in a hiking club, and while she felt she could no longer keep up with their pace and distance, she still wanted to get out and hike as much as possible. That she was able to do so with people who had faced similar diagnoses gave her a sense of camaraderie she found empowering (Campbell et al., 2004; Docherty, 2004). The ability for her to maintain - and build on - a connection to the local trail system was equally so. In fact, for Glenda, she found the trails to hold revitalized meaning for her as she coped with her "new normal" (Korpela et al., 2017). Glenda said that, "These forests and trails are a part of who 
I am, of who've I been, for a long, long time. There is no reason why I shouldn't be relying on them at this point in my life - they've always been there for me, and now I really need them." This aligns with Ratcliffe and Korpela (2016) assertion that natural environments can provide a sense of psychological escape through finding oneself in their connections with special places, like the hiking trails Glenda has enjoyed for so many years before.

Not all participants of the hiking program were able to come out on either the Wednesday or Saturday hike, and this was in large part due to ramifications of their illness and physical condition. Some found the unstable terrain, pace, and/or elevation gain (even if minimal) to be too challenging, and in some instances, potentially dangerous to their physical wellbeing. In light of those realities, there was still a draw to being outdoors in wilderness environments - it just required a little compromise.

Joy (58, breast cancer and osteosarcoma) relied on a walker and had other balance issues caused by her illness that prevented her from participating with the group, but she was still adamant to hike on a regular basis. Because of this, she and I would meet up for short jaunts on the flatter and less-challenging trails, often for only twenty minutes at a time due to her stamina. While she would have liked to go for longer distances, she found that even small, but regular, forays into the trails helped her feel better about herself and set aside some of the negative feelings that came with her situation. Morita et al. (2007) reported similar findings in the context of forest walking. Though Joy did not have the opportunity to hike with fellow survivors, she still did receive some of the benefit that came from the "collective enterprise of survivorship" because I could regale her with stories about others she had met through the hiking program in the past when she was able to come out with the group (Broom, Kenny, Kirby, \& Lwin, 2018). For Joy, the benefits of her time spent in nature, while short, were perceived as immensely valuable to her outlook and ability to be resilient in her health and illness-related regimens (Korpela et al., 2017). Because of this, Joy viewed her brief hikes as very meaningful to her ability to attend to her daily medical issues.

Each of the participants came to the hiking program with diverse experiences, but all for one reason: to embrace a nontraditional, and supportive, resource (hiking) as they fight cancer and accept their "new normal" to follow. That they built meaningful connections along the way - to the trails and forests, not to mention their fellow hikers - emphasizes the power of natural environments to be restorative and for people to find great value in place. Robyn (71, breast cancer), relished her opportunities to hike, because she said it allowed her to have a "greater appreciation for the preciousness of nature," something she was continually striving to learn more about, especially her role in helping to care for it. By being consistently immersed in the wilderness through the hiking program, Robyn found a "symbiotic relationship" with the land that made her feel both a "sense of responsibility," and a sense of "gratitude" for its "offerings."

\section{Conclusion}

Sometimes I go out to one of those trails by myself and sit and think about what I need to do to get better. I understand a lot of it is out of my control, but my doctor always said the most important thing for me to do is to be positive - to be resilient - even in the face of everything before me. Know where the best place is for me to find that positivity? Right 
out there on these trails. I'll sit for a minute before a hike, and just appreciate the beauty and am in awe of it. Then I go for a hike and I revel in the opportunity I have to feel a part of it all. - Roy (72, prostate cancer)

Natural environments are especially conducive for arousing awareness (Korpela \& Ylén, 2007; Ottosson \& Grahn, 2005), and time spent in wild places also allows opportunities for introspection and reflection (Connerty \& Knott, 2013), something that is essential for personal growth for those with cancer. While symptoms of stress, anxiety, and depression are common in those with cancer (Hoey et al., 2008), these data support a growing literature (Nutsford et al., 2013; Östergren et al., 2012) illustrating that issues of poor mental health significantly decrease after immersion in natural environments. This suggests that the embrace of a salutogenic approach to the treatment of cancer, which focuses more on the holistic wellbeing of patients, in order to deemphasize the "distinct causal links" of the illness is warranted (Jonas et al., 2006, p. 315). Jonas et al. suggest that the sociocultural benefits derived from friend and family support systems in tandem with self-perceived healing activities can "markedly change health outcomes, often to a greater extent than specific drug and even surgical treatments" (p. 316).

Natural landscapes can be important stimuli for the elicitation of memory as well (Ratcliffe \& Korpela, 2016); something that people who have faced tragedies or traumas like cancer can rely on to reconstruct their sense of self post-diagnosis of cancer (Harmon, 2019). As the self may need to be socially reconstructed after a diagnosis of cancer due to the imposition of the illness on one's life and its subsequent treatments (Ussher et al., 2006), socially constructed natural environments (Kyle \& Chick, 2007), then, may serve as an essential resource in finding the restoration and reinvigoration that is necessary for one to become healthy again (Morita et al., 2007).

For those with serious illnesses like cancer, the cultural identity associated with the esthetic natural landscape may be related to the illness trajectory: from illness, to diagnosis, to treatment, to life after illness, the natural environment is a continual process of restoration and rebirth in its own right (Korpela et al., 2015). In light of this, those with cancer may find the resources necessary to reignite their sense of resilience through finding great meaning in a sense of place (Kyle \& Chick, 2007) post-diagnosis of cancer.

This paper sought to answer the questions, does regular participation in a hiking group for survivors of cancer improve perceived wellbeing, and do cancer survivors develop positive meanings for natural environments as they negotiate their illness and recovery? As has been demonstrated by the participants' responses, overwhelmingly they were positively affected by their involvement in the hiking program, just as they found the natural environments to be cathartic, reinvigorating, and/or restorative in their own right as they navigated their illness, treatment, and recovery or health maintenance processes (Morita et al., 2007; Song et al., 2016; Wolsko \& Hoyt, 2012).

While the participants of this study found natural landscapes to be restorative to their sense of self as people fighting or recovering from cancer, further exploration is warranted on the diversity of places that can lend this essential spatial support to others experiencing traumatic life 
events (Korpela \& Hartig, 1996). A limitation of this study that could be explored in future research is the lack of control group to establish whether or not the social component or the immersion in natural environments was the more impactful factor. Future studies could explore the explicitly social aspects of immersion in natural environments.

What exactly is restorative is likely fluid and subjective to the individual, so there remains a need to better understand just what properties make a landscape therapeutic (Williams, 2002). Finally, and related, not everyone battling cancer will have the interest, or ability, to engage in a hiking program, though natural environments may still lend significant positive support (Kaplan \& Kaplan, 1989). Because of this, continued investigation into spending passive time in natural environments for those with cancer is also needed.

\section{Notes}

1. The pronouns "I," "me," and "we" refer to the first author throughout.

\section{References}

Abedalaal, M. S., \& Soebarto, V. (2019). Biophilia and salutogenesis as restorative design approaches in healthcare architecture. Architectural Science Review, 62(3), 195-205.

Antoni, M. H., Lehman, J. M., Kilbourn, K. M., Boyers, A. E., Culver, J. L., Alferi, S. M., ... Carver, C. S. \& ... (2001). Cognitive-behavioral stress management intervention decreases the prevalence of depression and enhances benefit finding among women under treatment for early-stage breast cancer. Health Psychology, 20(1), 20-32.

Baklien, B., Ytterhus, B., \& Bongaardt, R. (2016). When everyday life becomes a storm on the horizon: Families' experiences of good mental health while hiking in nature. Anthropology \& Medicine, 23(1), 42-53. doi:10.1080/13648470.2015.1056056

Beery, T., Jönsson, K. I., \& Elmberg, J. (2015). From environmental connectedness to sustainable futures: Topophilia and human affiliation with nature. Sustainability, 7(7), 88378854 .

Broom, A., Kenny, K., Kirby, E., \& Lwin, Z. (2018). The collective/affective practice of cancer survivorship. The British Journal of Sociology (4),1582-1601. doi:10.1111/1468-4446.12616

Buttimer, A., \& Seamon, D. (1980). The human experience of space and place. London: Croon Helm.

Campbell, H. S., Phaneuf, M. R., \& Deane, K. (2004). Cancer peer support programs - do they work? Patient Education and Counseling, 55(1), 3-15.

Capaldi, C. A., Passmore, H.-A., Nisbet, E. K., Zelenski, J. M., \& Dopko, R.

L. (2015). Flourishing in nature: A review of the well-being benefits of connecting with nature and its application as a positive psychology intervention. International Journal of

Wellbeing, 5(4), 1-16.

Cimprich, B., \& Ronis, D. L. (2003). An environmental intervention to restore attention in women with newly diagnosed breast cancer. Cancer Nursing, 26(4), 284-292. 
Connerty, T. J., \& Knott, V. (2013). Promoting positive change in the face of adversity:

Experiences of cancer and post-traumatic growth. European Journal of Cancer

Care, 22(3), 334-344.

Crist, E, Center for Environmental Philosophy, \& The University of North Texas.

(2004). Against the social construction of nature and wilderness. Environmental Ethics, 26(1), 526. doi:10.5840/enviroethics200426138

Crotty, M. (2010). The foundations of social research: Meaning and perspective in the research process. Thousand Oaks, CA: Sage.

Docherty, A. (2004). Experience, functions and benefits of a cancer support group. Patient Education and Counseling, 55(1), 87-93.

Fegg, M. J., Brandstätter, M., Kramer, M., Kögler, M., Haarmann-Doetkotte, S., \& Borasio, G. D. (2010). Meaning in life and palliative care. Journal of Pain and Symptom Management, 40(4), 502-509.

Fesenmaier, D. R., Goodchild, M. F., \& Lieber, S. R. (1981). Predicting recreation participation: The case of day hiking. Leisure Sciences, 4(4), 459-476.

Gianinazzi, M. E., for the Swiss Pediatric Oncology Group (SPOG), Rueegg, C.

S., Vetsch, J., Lüer, S., Kuehni, C. E., \& Michel, G. (2016). Cancer's positive flip side: Posttraumatic growth after childhood cancer. Supportive Care in Cancer, 24(1), 195-203.

Giuliani, M. V., \& Feldman, R. (1993). Place attachment in a developmental and cultural context. Journal of Environmental Psychology, 13(3), 267-274.

Goodwin, D., Peco, J., \& Ginther, N. (2009). Hiking excursions for people with disabilities: Experiences of interdependence. Therapeutic Recreation Journal, 43(1), 43-55.

Greider, T., \& Garkovich, L. (1994). Landscapes: The social construction of nature and the environment. Rural Sociology, 59(1), 1-24.

Harmon, J. (2019). Tell cancer to take a hike: Posttraumatic growth on the trail to recovery. Leisure/Loisir, 43(4), 459-478.

Hartig, T., Mang, M., \& Evans, G. W. (1991). Restorative effects of natural environments. Environment and Behavior, 23(1), 3-26.

Hay, R. (1998). Sense of place in a developmental context. Journal of Environmental Psychology, 18(1), 5-29.

Hoey, L. M., Ieropoli, S. C., White, V. M., \& Jefford, M. (2008). Systematic review of peersupport programs for people with cancer. Patient Education and Counseling, 70(3), 315-337.

Howell, A. J., Passmore, H., \& Buro, K. (2013). Meaning in nature: Meaning in life as a mediator of the relationship between nature connectedness and well-being. Journal of Happiness Studies, 14(6), 1681-1696.

Hull, B. R., IV, \& Stewart, W. P. (1995). The landscape encountered and experienced while hiking. Environment and Behavior, 27(3), 404-426. 
Janke, M. C., \& Jones, J. J. (2016). Using leisure to find a way forward after loss: A lifespan perspective. In D. A. Kleiber \& F. A. McGuire (Eds.), Leisure and human development (pp. 293-317). Urbana, IL: Sagamore.

Johansson, A.-C., Axelsson, M., Berndtsson, I., \& Brink, E. (2014). Illness perceptions in relation to experiences of contemporary cancer care settings among colorectal cancer survivors and their partners. International Journal of Qualitative Studies on Health and WellBeing, 9(1), 23511-23581.

Johnson, C. Y. (1998). A consideration of collective memory in African American attachment to wildland recreation places. Research in Human Ecology, 5(1), 5-15.

Jonas, W. B., Beckner, W., \& Coulter, I. (2006). Proposal for an integrated evaluation model for the study of whole systems health care in cancer. Integrative Cancer Therapies, 5(4), 315-319.

Kaplan, R., \& Kaplan, S. (1989). The experience of nature: A psychological perspective. Cambridge: Cambridge University Press.

Kaplan, S. (1995). The restorative benefits of nature: Toward an integrative framework. Journal of Environmental Psychology, 15(3), 169-182.

Kleiber, D. A., Hutchinson, S. L., \& Williams, R. (2002). Leisure as a resource in coping with negative life events: Self-protection, self-restoration, and personal transformation. Leisure Sciences, 24(2), 219-235.

Korpela, K., De Bloom, J., \& Kinnunen, U. (2015). From restorative environments to restoration in work. Intelligent Buildings International, 7(4), 215-223.

Korpela, K., \& Hartig, T. (1996). Restorative qualities of favorite places. Journal of Environmental Psychology, 16(3), 221-233.

Korpela, K., Nummi, T., Lipiäinen, L., De Bloom, J., Sianoja, M., Pasanen, T., \& Kinnunen, U. (2017). Nature exposure predicts well-being trajectory groups among employees across two years. Journal of Environmental Psychology, 52, 81-91.

Korpela, K. M., \& Ylén, M. (2007). Perceived health is associated with visiting natural favourite places in the vicinity. Health \& Place, 13(1), 138-151. doi:10.1016/j.healthplace.2005.11.002

Korpela, K. M., Ylén, M., Tyrväinen, L., \& Silvennoinen, H. (2008). Determinants of restorative experiences in everyday favorite places. Health \& Place, 14(4), 636-652.

doi:10.1016/j.healthplace.2007.10.008

Kyle, G. T., \& Chick, G. (2007). The social construction of a sense of place. Leisure Sciences, 29(3), 209-225. doi:10.1080/01490400701257922

Kyle, G. T., Graefe, A., Manning, R., \& Bacon, J. (2003). An examination of the relationship between leisure activity involvement and place attachment among hikers along the Appalachian Trail. Journal of Leisure Research, 35(3), 249-273.

Kyle, G. T., Mowen, A. J., \& Tarrant, M. (2004). Linking place preferences with place meaning: An examination of the relationship between place motivation and place attachment. Journal of Environmental Psychology, 24(4), 439-454. 
Lee, J., Tsunetsugu, Y., Takayama, N., Park, B.-J., Li, Q., Song, C., ... Miyazaki, Y. (2014). Influence of forest therapy on cardiovascular relaxation in young adults. Evidence-Based Complementary and Alternative Medicine, 1, 1-7.

Low, S. M., \& Altman, I. (1992). Place attachment: A conceptual inquiry. In I. Altman \& S. M. Low (Eds.), Place attachment (pp. 1-12). New York, NY: Plenum Press.

Maas, J., van Dillen, S. M. E., Verheij, R. A., \& Groenewegen, P. P. (2009). Social contacts as a possible mechanism behind the relation between green space and health. Health \& Place, 15(2), 586-595. doi:10.1016/j.healthplace.2008.09.006

Mayer, F. S., \& Frantz, C. P. (2004). The connectedness to nature scale: A measure of individuals' feelings in community with nature. Journal of Environmental Psychology, 24(4), 503-515.

Mayer, F. S., Frantz, C. P., Bruehlman-Senecal, E., \& Dolliver, K. (2009). Why is nature beneficial? The role of connectedness to nature. Environment and Behavior, 41(5), 607-643.

Milligan, M. J. (1998). Interactional past and potential: The social construction of place attachment. Symbolic Interaction, 21(1), 1-33.

Mitchell, R., \& Popham, F. (2008). Effect of exposure to natural environment on health inequalities: An observational population study. The Lancet, 372(9650), 1655-1660.

Morita, E., Fukuda, S., Nagano, J., Hamajima, N., Yamamoto, H., Iwai, Y., ... Shirakawa, T. (2007). Psychological effects of forest environments on healthy adults: Shinrinyoku (forest-air bathing, walking) as a possible method of stress reduction. Public Health, 121(1), 54-63. doi:10.1016/j.puhe.2006.05.024

Morris, B. A., Campbell, M., Dwyer, M., Dunn, J., \& Chambers, S. K. (2011). Survivor identity and post-traumatic growth after participating in challenge-based peer-support programmes. British Journal of Health Psychology, 16(3), 660-674.

Nutsford, D., Pearson, A. L., \& Kingham, S. (2013). An ecological study investigating the association between access to urban green space and mental health. Public Health, 127(11), 1005-1011.

Östergren, P. O., Björk, J., Grahn, P., Skärbäck, E., \& Währborg, P. (2012). Green qualities in the neighbourhood and mental health - Results from a longitudinal study in Southern Sweden. BMC Public Health, 12, 337-347.

Ottosson, J., \& Grahn, P. (2005). A comparison of leisure time spent in a garden with leisure time spent indoors: On measures of restoration in residents in geriatric care. Landscape Research, 30(1), 23-55.

Park, B.-J., Furuya, K., Kasetani, T., Takayama, N., Kagawa, T., \& Miyazaki, Y. (2011). Relationship between psychological responses and physical environments in forest settings. Landscape and Urban Planning, 102(1), 24-32.

Park, C. L., Chmielewski, J., \& Blank, T. O. (2010). Post-traumatic growth: Finding positive meaning in cancer survivorship moderates the impact of intrusive thoughts on adjustment in younger adults. Psycho-Oncology, 19(11), 1139-1147. 
Patton, M. (1990). Qualitative evaluation and research methods. Newbury Park, CA: Sage Publications.

Proctor, J. D. (1998). The social construction of nature: Relativist accusations, pragmatist and critical realist responses. Annals of the Association of American Geographers, 88(3), 352-376. doi:10.1111/0004-5608.00105

Ratcliffe, E., \& Korpela, K. M. (2016). Memory and place attachment as predictors of imagined restorative perceptions of favourite places. Journal of Environmental Psychology, 48, 120-130.

Rolston, H., III. (2001). Natural and unnatural, wild and cultural. Western North American Naturalist, 61(3), 267-276.

Saldaña, J. (2012). The coding manual for qualitative researchers. Thousand Oaks, CA: Sage.

Scannell, L., \& Gifford, R. (2010). Defining place attachment: A tripartite organizing framework. Journal of Environmental Psychology, 30(1), 1-10.

Scrignaro, M., Barni, S., \& Magrin, M. E. (2011). The combined contribution of social support and coping strategies in predicting post-traumatic growth: A longitudinal study of cancer patients. Psycho-Oncology, 20(8), 823-831.

Song, C., Ikei, H., \& Miyazaki, Y. (2016). Physiological effects of nature therapy: A review of the research in Japan. International Journal of Environmental Research and Public Health, 13, 781-798.

Stokowski, P. A. (2002). Languages of place and discourses of power: Constructing new senses of place. Journal of Leisure Research, 34(4), 368-382.

Svarstad, H. (2010). Why hiking? Rationality and reflexivity within three categories of meaning construction. Journal of Leisure Research, 42(1), 91-110.

Tedeschi, R. G., \& Calhoun, L. G. (2004). Posttraumatic growth: Conceptual foundations and empirical evidence. Psychological Inquiry, 15(1), 1-18.

Tracy, S. (2013). Qualitative research methods: Collecting evidence, crafting analysis, communicating impact. Hoboken, NJ: Wiley-Blackwell.

Tuan, Y. (1973). Topophilia: A study of environmental perception, attitudes, and values. Englewood Cliffs, NY: Prentice-Hall.

Tuan, Y. F. (1980). Rootedness versus sense of place. Landscape, 24, 3-8.

Twohig-Bennett, C., \& Jones, A. (2018). The health benefits of the great outdoors: A systematic review and meta-analysis of greenspace exposure and health outcomes. Environmental Research, 166, 628-637.

Ulrich, R. S. (1979). Visual landscapes and psychological well-being. Landscape Research, 4(1), 17-23. doi:10.1080/01426397908705892

Ussher, J., Kirsten, L., Butow, P., \& Sandoval, M. (2006). What do cancer support groups provide which other supportive relationships do not? The experience of peer support groups for 
people with cancer. Social Science \& Medicine, 62(10), 2565-2576.

doi:10.1016/j.socscimed.2005.10.034

Williams, A. (2002). Changing geographies of care: Employing the concept of therapeutic landscapes as a framework in examining home space. Social Science \& Medicine, 55(1), 141154.

Williams, D. R., Patterson, M. E., Roggenbuck, J. W., \& Watson, A. (1992). Measuring place attachment: Some preliminary results. In L. H. McAvoy \& D. Howard (Eds.), Abstracts: 1989 Leisure Research Symposium (p. 32). Arlington, VA: NRPA.

Wilson, E. O. (1993). Biophilia and the conservation ethic. In R. Kellert \& E.

O. Wilson (Eds.), The biophilia hypothesis (pp. 31-41). Washington, DC: Island Press.

Winefield, H. R., Coventry, B. J., Lewis, M., \& Harvey, E. J. (2003). Attitudes of patients with breast cancer toward support groups. Journal of Psychosocial Oncology, 21(2), 39-54.

Wolsko, C., \& Hoyt, K. (2012). Employing the restorative capacity of nature: Pathways to practicing ecotherapy among mental health professionals. Ecopsychology, 4(1), 10-24. 